\title{
Analysis of Online System Investment Decision Dependency on Customer Profile and Equipment Condition via Risk Approach
}

\author{
Mohd Radzian Abdul Rahman* ${ }^{\mathrm{a}}$, Mohd Fadzil Siamª ${ }^{\mathrm{a}}$ Mohd Iqbal Ridwan", \\ Rosila Senan ${ }^{\mathrm{b}}$, Muhammad Azizi Abdul Rahman ${ }^{\mathrm{b}}$ \\ ${ }^{a}$ Smart Grid Unit, TNB Research Sdn. Bhd. No.1, Lorong Ayer Hitam, Kawasan Penyelidikan Bangi, 47300 Kajang, Malaysia \\ ${ }^{b}$ Asset Management Unit, Engineering Department, TNB Distribution Division, Jalan Timur, Petaling Jaya, Selangor, Malaysia
}

\begin{abstract}
Real-time online monitoring system and its analytics system for substation equipment is an important element of smart grid technology. However, proposals to invest in real-time online monitoring system are often turned down by the decision-maker due to the lack of economic model which act as a qualifier that determines whether the investment is worthwhile for the company and nation. In this paper, by deploying risk quantification methodology, visualized through decision tree structures, we propose that the investment of a sophisticated system for substation monitoring is dependent on customer segment profile and the condition of equipment. We present several scenarios that depict our argument on this matter.
\end{abstract}

Keywords: Online monitoring, investment decision, risk analysis, decision-tree, economic model, decision-making

\section{Introduction}

Many electricity utility companies are contemplating to install real-time monitoring system to monitor the condition of substation equipment as a part of the effort to enhance the reliability of substation equipments [1] and reduce monetary losses. This is due to the following reason - "it is common that imminent failures of substation equipment could not be detected in advance by using non-automated condition based maintenance regime, leading to undesired losses". The root-cause of undetected failures is the nature of the fault, which progresses faster than the pre-determined inspection interval. Thus, a realtime condition monitoring system that continuously monitors substation equipments 24 hours a day is considered as more effective in detecting incipient fault compared to condition based monitoring (CBM) regime that monitor the equipment in a periodical manner (example: once in 3 months, once in a year and etc.). However, to know only the intangible [2] benefits on hand is somehow not sufficient because the decision-maker may require the quantification of the benefits to justify whether the investment in a particular location gives a return that is comparable to the cost of investment [3], [4].

In this paper, we applied the theory of risk analysis to compare the risk (expected loss) of non-real time monitoring methodology and the risk (expected loss) of real-time monitoring methodology. The benefit of real-time monitoring system is quantified as the difference between the risk of non real-time monitoring system and the risk of real-time monitoring system. Subsequently, we present some cases where the benefits of having a real-time monitoring system are dependent on two factors that are the condition of equipment and the customer profile of the electricity network supplied by the equipment.

\section{Risk Analysis by Using Decision Tree and Cost-Benefit Analysis}

Risk is constructed based on three elements $\left(S_{i}, P_{i}, E_{i}\right)$, where $S_{i}$ represents the $i$ th scenario, $P_{i}$ and $E_{i}$ represent the probability and the consequence of the $i$ th scenario.

\footnotetext{
* Manuscript received June 15, 2012; revised August 14, 2012.

Corresponding author. Tel.: +60-10-2217205; E-mail address: radzian.rahman@me.com.
} 
Specifically, risk of equipment failure in the scenario when a real-time monitoring system is deployed in a substation, is defined as the equation below:

$$
R_{\mathrm{RT}}=P_{\mathrm{RT}}(\text { loss }) E_{\mathrm{RT}}(\text { loss })
$$

where $R_{\mathrm{RT}}$ is defined as risk given real time monitoring system, $P_{\mathrm{RT}}($ loss $)$ is defined as the probability of losses given real time monitoring system, and $E_{\mathrm{RT}}$ (loss) is defined as expected monetary value of loss due to undetected failure.

In similar manner, risk of equipment failure in the scenario when non real-time monitoring system is deployed in a substation, is defined as the equation below:

$$
R_{\mathrm{NRT}}=P_{\mathrm{NRT}}(\text { loss }) E_{\mathrm{NRT}}(\text { loss })
$$

where $R_{\mathrm{NRT}}$ is defined as risk without real time monitoring system, $P_{\mathrm{NRT}}($ loss $)$ is defined as the probability of loss without real time monitoring system; and $E_{\mathrm{NRT}}$ (loss) is defined as expected monetary value of losses due to undetected failure.

\subsection{Risk analysis by using decision tree}

In practice, the calculation of the probability of losses requires the information of the likelihood of several mutually exclusive events to happen that resulted in the eventual losses. The structure of a risk model can be more vividly illustrated by decision tree diagrams [5]-[7]. Fig. 1 illustrated the decision tree diagram of the risk associated with real-time monitoring system.

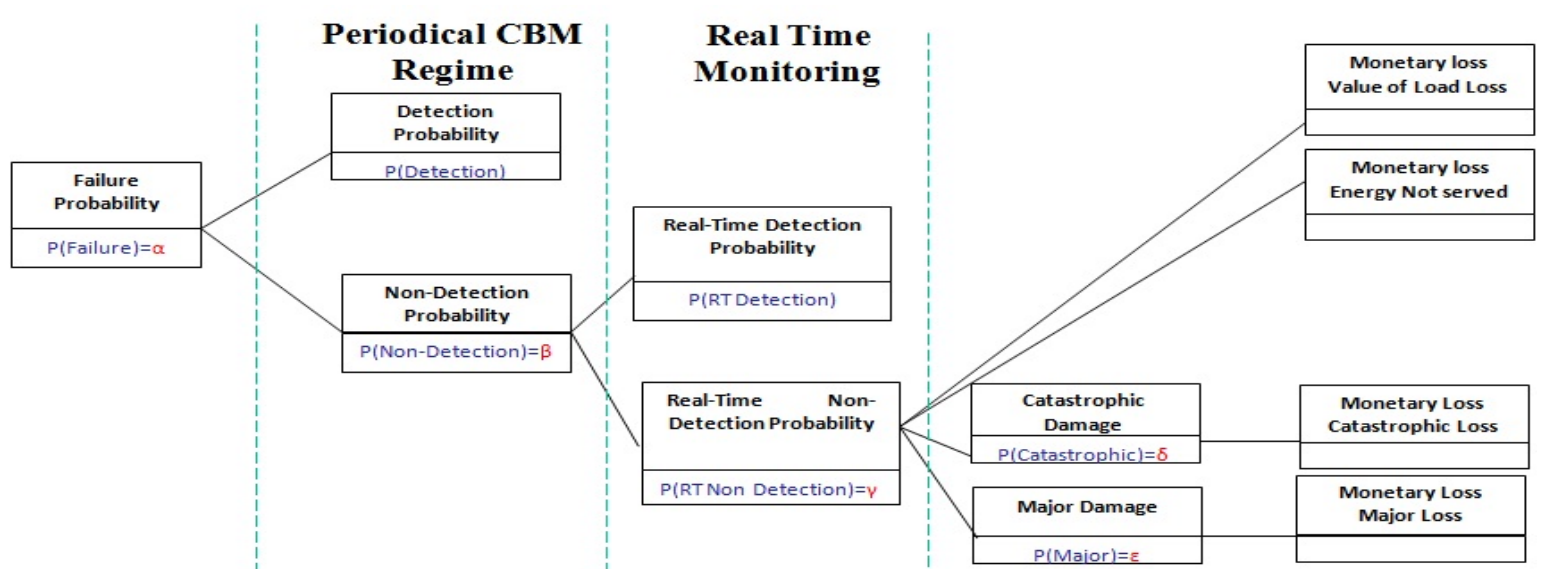

Fig. 1. Decision tree for real-time monitoring system.

As shown in the furthest right section of Fig. 1, the losses due to equipment failure are segmented into four types. The first loss segment is the value of load loss [8] which represents the losses incurred by customer. The second segment of losses is the value of energy not served, which represents the value of loss of sales of electricity to the customer. The third segment of losses is catastrophic loss, which is the cost of damage that is inflicted to the whole substation due to an accident. An example of a catastrophic loss is an explosion which causes damages to other equipments or substation. The fourth segment of losses is major loss, which is the damage contained within the failed equipment itself.

The risk of real-time condition monitoring system can be quantified by

$$
R_{\mathrm{RT}}=\alpha \beta \gamma \delta \text { (catastrophic loss) }+\alpha \beta \gamma \varepsilon \text { (major loss) }+\alpha \beta \gamma(\mathrm{VOLL}+\mathrm{ENS})
$$

where $\alpha$ represent equipment failure probability, $\beta$ represents probability of non detection by CBM regime, $\gamma$ represents probability of non-detection by real time monitoring, $\delta$ represents the probability of catastrophic failure and $\varepsilon$ represents the probability of major failure. In layman term, risk associated with real-time monitoring equipment is the product of the percentage of non-detection of equipment failure using real-time monitoring equipment and the losses associated to it. 


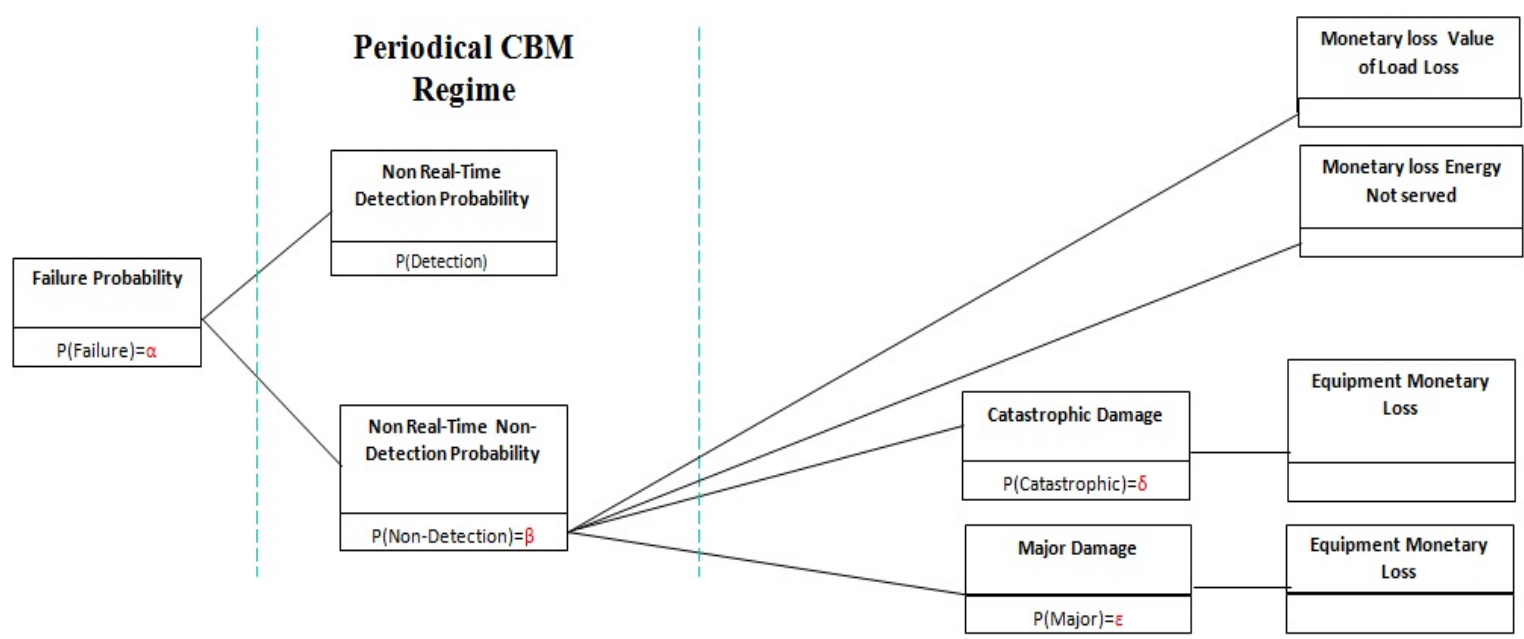

Fig. 2. Risk of non-real time monitoring regime.

The risk associated with non-real time monitoring system is shown in Fig. 2. The risk of non-real time monitoring regime can be quantified by using the equation below:

$$
\left.\left.R_{\mathrm{NRT}}=\alpha \beta \delta \text { (catastrophic loss }\right)+\alpha \beta \varepsilon \text { (major loss }\right)+\alpha \beta(\text { VOLL }+ \text { ENS })
$$

\subsection{Benefit of real-time monitoring system}

From the calculation of risk in Eq. (3) and Eq. (4), the benefit of utilizing real-time monitoring system is the difference between $R_{\mathrm{NRT}}$ and $R_{\mathrm{RT}}$, as given by the following equation:

Benefit $(\$ /$ Year $)=(1-\gamma) \alpha \beta[\delta($ catastrophic loss $)+\varepsilon($ major loss $)+($ VOLL + ENS $)]$

\subsection{Dependency on epistemic probability of equipment failure and value of load loss}

As shown in Eq. (5), the benefit associated with implementing real-time monitoring system varies linearly with the probability of equipment failure, probability of non-detection and the losses components.

During the life-cycle of similar equipments in a substation, major loss and catastrophic loss remain constant. The probability of non-detection of failure is a random process, valued as a constant.

However, the probability of equipment failure and VOLL vary equipment state of health and customer movement, respectively. Probability of equipment failure can be modeled from the existing non real-time condition monitoring regime data. In addition, the value of load loss (VOLL) varies when new customers move into the area or move out from the area. Thus, the benefit of installing a real-time monitoring system may vary significantly with respect to equipment condition and customer segment profile; and in the next sub-sections, we discuss about the probability of equipment failure and value of load loss quantification.

\section{A. Epistemic probability of failure model as a function of equipment condition parameter}

Probability can be expressed in term of aleatory probability or epistemic probability. Aleatory probability is derived from the frequentist approach, which uses the "frequency" of an event to occur as the basis of the probability mass. In condition based monitoring, an event of equipment failure is very rare such that it is quite difficult to construct a model of failure probability across the condition parameter by using the existing data. Thus, epistemic probability that does not follow strictly the "frequentist calculation" is more convenient to indicate a probable failure to occur.

In this paper, a method that was described in [9], [10] is utilized to model the probability of failure with respect to equipment condition parameter. For the benefit of reader, the calculation method is restated in this paper. At each condition parameter value of equipment failure event, the probability assigned to failure event is calculated by using the following equation: 


$$
P_{j k}(\text { failure })=\frac{\sum_{Y=Y j k}^{Y=Y_{\max }} F\left(y_{j k}\right)}{\sum_{Y=Y_{j k}}^{Y=Y_{\max }} F\left(y_{j k}\right)+\sum_{Y=0}^{Y=Y_{j k}} N\left(y_{j k}\right)}
$$

where $P_{j k}$ (failure) is the probability assigned to proposition equipment failure at " $Y_{j}$ "th (where $Y_{j}$ is the measured value of " $j$ "th condition parameter $\left.Y_{j}=\left\{0, . ., y_{j}, . ., Y_{j \max }\right\}\right)$ and " $k$ "th equipment failure; $F\left(y_{j k}\right)$ is the number of equipment which failed at $y_{j}$ value, and $N\left(y_{j k}\right)$ is the number of equipments which have not failed (including normal operating equipments and equipments with incipient fault condition) at $y_{j} \mathrm{ppm}$.

From the equation above, several data of $P_{j k}$ (failure) that corresponds to value of $y_{j k}$ were obtained and modeled as a cumulative Weibull function. The probability of equipment failure is calculated as

$$
P(\text { failure })=1-\exp \left[-\left(\frac{y_{j}}{\mu}\right)^{\lambda}\right]
$$

where $\mu$ is the life characteristics and $\lambda$ is the shape parameter.

\section{B. Value of load loss}

Value of load loss is defined as the aggregated value of customer outage cost across the whole range of customers in the power network. Basically, the VOLL $(\$ / \mathrm{kWh})$ is segmented to three broad customer profile category which are 1) domestic customer, 2) commercial customer and 3) industrial customer. Within the broad customer segment, VOLL can be further segmented to a number of sub-categories; and for each sub-category, customer outage cost (VOLL) is a function of several factors, such as business type, time of the day and etc. A survey [8] was conducted to determine the customer outage cost across Malaysia for each sub-category.

The VOLL of a broad customer segment is the composite of the VOLL of customer sub-category and weighted by the electricity consumption profile. As an example, the value of VOLL for broad industrial customer category is calculated by

$$
\operatorname{VOLL}_{I}=\operatorname{VOLL}_{I_{1}}\left(\frac{\mathrm{kWh}_{I_{1}}}{\mathrm{kWh}_{I}}\right)+\operatorname{VOLL}_{I_{2}}\left(\frac{\mathrm{kWh}_{I_{2}}}{\mathrm{kWh}_{I}}\right)+\ldots+\operatorname{VOLL}_{I_{n}}\left(\frac{\mathrm{kWh}_{I_{n}}}{\mathrm{kWh}_{I}}\right)
$$

where $\mathrm{VOLL}_{I}$ is the value of load lost of broad industrial customer segment, $\mathrm{VOLL}_{I n}$ is the value of load lost of " $n$ "th industrial customer sub-category, $\mathrm{kWh}_{I_{n}}$ is the electricity consumption of $n$th industrial customer sub-category and $\mathrm{kWh}_{I}$ is the electricity consumption of broad industrial customer segment.

In similar manner, the VOLL of a particular area is calculated, as stated in Equation (9) below:

$$
\operatorname{VOLL}_{A}=\operatorname{VOLL}_{I}\left(\frac{\mathrm{kWh}_{I}}{\mathrm{kWh}_{\text {total }}}\right)+\operatorname{VOLL}_{D}\left(\frac{\mathrm{kWh}_{D}}{\mathrm{kWh}_{\text {total }}}\right)+\operatorname{VOLL}_{C}\left(\frac{\mathrm{kWh}_{C}}{\mathrm{kWh}_{\text {total }}}\right)
$$

where $\operatorname{VOLL}_{A}$ is the cost of in a particular area "A", D denotes domestic customer segment, $\mathrm{C}$ denotes commercial customer segment, $\mathrm{kWh}_{\text {total }}$ denotes the total electricity consumed in area "A".

We consider the VOLL of broad customer segment to simplify our calculation.

\section{Dependency of investment decision on customer profile and condition of equipment}

To decide whether the investment is worthy, the equipment life-span benefit of online monitoring system is compared with the life-span cost of investment in real-time monitoring system.

\subsection{Cost of investment in real-time online monitoring system}

Cost associated with investing in real time monitoring system is presented by the equation below: 


$$
\operatorname{Cost}(\$ / \text { year })=\frac{C_{\mathrm{RT}}+C_{\mathrm{LS}}}{N}
$$

where $C_{\mathrm{RT}}$ denotes the initial real-time monitoring system, $C_{\mathrm{LS}}$ denotes life span maintenance cost and " $N$ " denotes the number of years of life-span monitoring equipment life-span.

\subsection{Significance of the customer segment profile and probability of equipment failure}

To describe the significance of customer profile and probability of equipment failure elements in the decision-making process, we investigated three scenarios; that are 1) domestic customer segment dominance scenario, (2) industrial customer segment dominance scenario and 3) domestic customer segment dominance with increased equipment probability of failure.

The following hypothetical values are assigned to the elements involved in calculating the benefit of real time monitoring system, shown in Table 1.

Table 1: Assigned hypothetical values

\begin{tabular}{lll}
\hline No. & Term & Values \\
\hline 1. & Probability of equipment failure $(\alpha)$ & 0.01 \\
3. & Probability of non detection of non real-time monitoring $(\beta)$ & 0.7 \\
5. & Probability of non detection of real-time monitoring $(\gamma)$ & 0.2 \\
6. & Probability of catastrophic loss $(\delta)$ & 0.2 \\
7. & Probability of major loss $(\varepsilon)$ & 0.8 \\
8. & Equipment loading & $10 \mathrm{MW}$ \\
9. & Major loss & $\$ 1,000,000$ \\
10. & Catastrophic loss & $\$ 3,000,000$ \\
11. & Outage duration (Worst case scenario : Replacing equipment) & 720 hours \\
12. & Value of Load Loss Domestic Customer Segment $\left(\mathrm{VOLL}_{\mathrm{D}}\right)$ & $\$ 0.49 / \mathrm{kWh}$ \\
13. & Value of Load Loss Commercial Customer Segment $\left(\mathrm{VOLL}_{\mathrm{C}}\right)$ & $\$ 9.59 / \mathrm{kWh}$ \\
14. & Value of Load Loss Industrial Customer Segment $\left(\mathrm{VOLL}_{\mathrm{I}}\right)$ & $\$ 57.9 / \mathrm{kWh}$ \\
15. & Electricity Tariff $(\$ / \mathrm{MWh})$ & 300 \\
16. & Investment cost of online monitoring system $\left(\mathrm{C}_{\mathrm{RT}}\right)$ & $\$ 1,000,000.00$ \\
17. & Maintenance cost of online monitoring system $\left(\mathrm{C}_{\mathrm{LS}} / \mathrm{N}\right)$ & $\$ 5,000 /$ year \\
18. & Life Span of online monitoring system & 20 years \\
\hline
\end{tabular}

The outage duration is considered from the perspective of worst case scenario of time to replace failed equipment. Loss due to energy not serve is calculated as [electricity tariff] $\times$ [equipment loading] $\times$ [outage duration]. Value of load loss is calculated as [VOLL] $\times$ [equipment loading] $\times$ [outage duration]. The total cost of the online monitoring system for its entire life span is $\$ 1,100,000.00$. Now, let us consider the scenarios:

Scenario 1: Industrial customer segment dominance

Assume the percentages of power consumed in industrial customer segment dominance area are as the following; $10 \%$ of power consumed by domestic customer, $20 \%$ of power consumed by commercial customer and $70 \%$ of power consumed by industrial customer. Using Eq. (5) and Eq. (9), the benefit of online monitoring system is around $\$ 1.7$ million.

Since the benefit of real-time monitoring system is greater than total cost of online monitoring system (\$1.1million), the cost-benefit computation prompts the decision-maker to install the monitoring system for this area.

Scenario 2: Domestic customer segment dominance

Assume the percentages of power consumed in domestic customer segment dominance area are as the following; $90 \%$ of power consumed by domestic customer, and $10 \%$ of power consumed by commercial customer. Using Eq. (5) and Eq. (9), the benefit of online monitoring system is around $\$ 70$ thousands.

Since the benefit of real-time monitoring system is less than the total cost of online monitoring system (\$1.1million), the computation prompts the decision-maker that there is insufficient incentive to install real-time monitoring system in this area.

Scenario 3: Domestic customer segment dominance \& higher equipment failure probability 
Assume the percentages of power consumed in domestic customer segment dominance area are similar with Scenario 2, and from Eq. (7), we assume the probability of equipment failure increased to 0.2. Using Eq. (5), the benefit of online monitoring system is obtained as $\$ 1.5$ million.

Since the benefit of real-time monitoring system is greater than total cost of online monitoring system, (\$1.1million) the computation prompts the decision-maker to install real-time monitoring system for this area.

Through the calculation done in Section 3.1, the benefit of Scenario 1 is greater than the cost of the investment, thus it is feasible to invest in real-time online monitoring system for area with industrial customer dominance of that particular detail. On the other hand, the investment in real-time online monitoring system for domestic customer area dominance is only feasible when equipment failure probability has increased to a certain degree.

The decision "GO" or "NO-GO" with the investment plan is governed by the following inequality. The decision-maker decides "GO" with the investment plan when Benefit>Cost and "NO-GO" when Cost $>$ Benefit. Given the VOLL of broad customer segment remains constant, that is, the electricity supplied by the substation is continuously feed to the same customer profile; from the probability of equipment failure perspective, the probability mass that will prompt the decision-maker to make a "GO" decision is governed by the following inequality:

$$
\alpha>\frac{C_{\mathrm{RT}}+C_{\mathrm{LS}}}{N \beta(1-\gamma)(\delta(\text { catastrophic loss })+\varepsilon(\text { major loss })+(\text { VOLL }+ \text { ENS }))}
$$

The segmentation of investment decision w.r.t. probability of equipment failure is depicted as in Fig. 3. On the other hand, given the probability of equipment failure remains constant, from the customer segment profile perspective, the VOLL which will prompt the decision-maker to make a "GO" decision is governed by the following inequality:

$$
\mathrm{VOLL}>\frac{C_{\mathrm{RT}}+C_{\mathrm{LS}}}{\alpha \beta(1-\gamma) N}-(\delta(\text { catastrophic loss })+\varepsilon(\text { major loss })+\mathrm{ENS})
$$

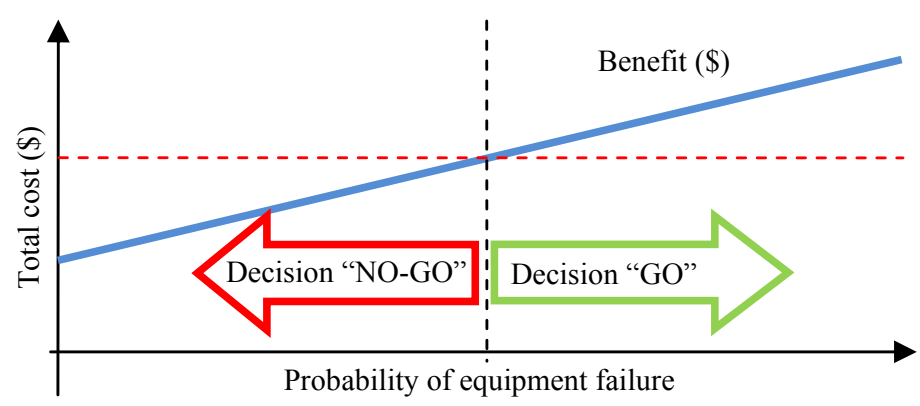

Fig. 3. Segmentation of investment decision with respect to probability of equipment failure

The segmentation of investment decision with respect to VOLL is illustrated as in Fig. 4.

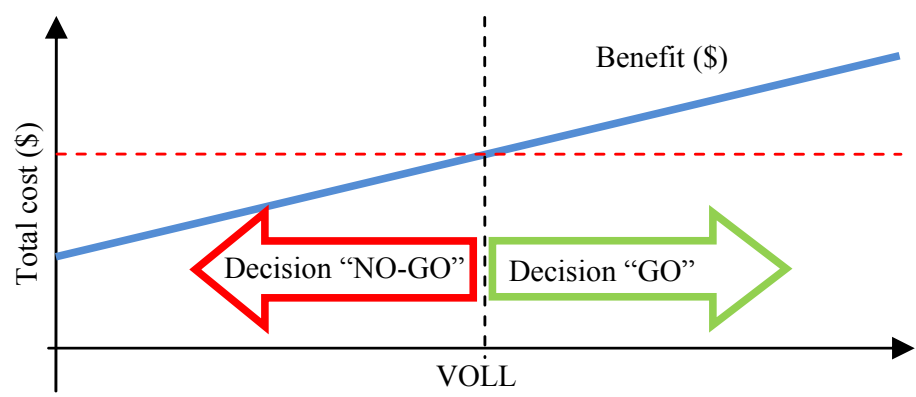

Fig. 4. Segmentation of investment decision with respect to VOLL. 
Note that the scenario depicted in this section refer to situation where benefit due to reduction of major loss, catastrophic loss and energy not served is less than the capital cost and maintenance cost of the equipment, or mathematically, $N(1-\gamma) \alpha \beta[\delta$ (catastrophic loss) $+\varepsilon$ (major loss) $+(\mathrm{ENS})]<C_{\mathrm{LS}}+C_{\mathrm{RT}}$.

\section{Limitation}

Other cost and benefit elements such as the benefit of delaying the replacement of equipment and the cost of degraded system operation will be considered in future work. Currently, we are lacking sufficient data to appropriate model those variables in this paper. The "time value of money" will also be introduced in future work.

\section{Conclusion}

In this paper, we have analyzed the dependency of real-time monitoring system investment decision on customer profile and probability of equipment failure. This is done through comparing the risk reduction benefit with the investment and maintenance cost of the monitoring system. To showcase the significance of those varying factors, three hypothetical scenarios were introduced. The mathematical limiting values of VOLL and failure probability that satisfy the investment decision constraints were presented. Finally, we reemphasized the importance to consider the two varying elements that are the customer profile and probability of equipment failure to effectively select the suitable situation and location to install the realtime on-line monitoring system.

\section{References}

[1] Andersson G, et al. Causes of 2003 major grid blackouts in North America and Europe, and recommended means to improve system dynamic performance. IEEE Transactions on Power Systems, 2005; 20(4).

[2] Joseph H. et al. An examination of temporal trends of electricity reliability based on reports from U.S. electric utilities. Ernest Orlando Lawrence Berkeley National Laboratory, January 2012.

[3] Impact Analysis Approach - Distribution System Reliability Webinar. U.S. Department of Energy, February 2012.

[4] Adamec M, Pavlatka P, Stary O. Costs and benefits in smart grid and accumulation in Czech distribution system", Energy Procedia, 2011; 12:67-75.

[5] Haymes YY. Risk modelling, assessment and management. Wiley Series in System Engineering and Management, 1998.

[6] Li W. Risk assessment of power systems: models, methods, and applications. IEEE Press Series on Power Engineering, 2004.

[7] Aven T. On when to base event trees and fault trees on probability models and frequentist probabilities in quantitative risk assessments. International Journal of Performability Engineering, 2012; 8(3):311-320.

[8] Hisham A, et al. Report on the determining the value of load loss in the Malaysian electricity supply industry. TNB Research Report, 2006.

[9] Rahman RMA. Diagnosis decision-making for safe and effective operation of power transformer. PhD dissertation. University of Tsukuba, Japan, March 2012.

[10] Rahman RMA, Itoh M, Inagaki T. An application of Weibull curve fitting model and introduction of DS theoretical framework concept on determining the risk of power transformer. Presented at: Proceeding Asian Network Quality Congress, 2009. 